\title{
The vertical dimensions of the face and skeletodental retrognathism
}

\author{
W. STUART HUNTER, D.T.S., M.S., PI. D. \\ Ann Arbor, Mich.
}

THE purpose of this study was to compare vertical dimensions in the faces of a sample of skeletodental retrognathic (Class II) subjects with those of a sample of skeletodental orthognathic (Class I) subjects. Differences in vertical dimensions of the face between normal and retrognathic faces would be of considerable interest in the study of the inheritance of malocelusion, since in a study of twins ${ }^{6}$ it was found that the vertical dimensions of the face are more frequently inheritcd than the anteroposterior dimensions. Further, Fisk and associates ${ }^{4}$ and Graber, ${ }^{2}$ in summary papers, have indicated that the essential nature of Class II malocelusion is in a posterior position of the mandible. More recently, Harris $^{5}$ has confirmed this and found, in addition, that the mandible is, on the average, smaller in persons with Class II malocelusion than in Class I subjects.

Thus, one would not be surprised to find vertical differences between retrognathic and orthognathic faces. Indeed, Schudy ${ }^{9}$ has been able to establish such differences by sorting his samples according to the degree of divergence of the angle that the mandibular plane makes with sella-nasion to provide a clinically useful concept of vertical differences.

Similarly, Sassouni and Nanda ${ }^{8}$ have reported on the vertical differences between persons with deep-bite and those with open-bite. They found that there was greater maxillary alveolar height in open-bite than in deep-bite and that open-bite was associated with a wider mandibular plane angle and a more posteriorly and inferiorly positioned chin than deep-bite.

However, in a comparison of children with normal occlusion and malocclusion, Weinberg and Kronman ${ }^{10}$ found no significant proportional differences in anterior vertical components of face height between their normal sample and their untreated Class II sample.

From the Department of Orthodontics and the Center for Human Growth and Development, University of Michigan. 


\section{THE SAMPLES}

The skeletodental orthognathic sample was selected from the files of the University of Michigan Elementary School Growth Study so that, in so far as possible, each subject had a facial pattern within the ranges established for the Northwestern analysis. ${ }^{2}$ All subjects were between 10 years 6 months and 11 years 5 months of age. The molar relationship was Class I, and the ANB angle was less than 4.5 degrees for all subjects. Records were found for thirteen boys and twelve girls who met these qualifications. Table I shows the means published for the ten values used from the Northwestern analysis ${ }^{2}$ and the averages for this sample. The average values for thirteen boys and twelve girls are quite similar to the Northwestern standards, except for the measurements which indicate more protrusive dentitions in the Growth Study sample.

The retrognathic (Class II) sample was selected both from the files of the Universtiy of Michigan Elementary School Growth Study and from the clinic files of the Department of Orthodontics. All records used were pretreatment and were obtained when the subjects were between 10 years 6 months and 11 years 5 months of age. For this sample, the molar relationship was Class II (that is, end-to-end to full cusp or greater) and the ANB angle was greater than 4.5 degrees for all subjects. Twenty-five boys and twenty-five girls were so selected.

Since the criteria of a Class II molar relationship and an ANB angle of greater than 4.5 degrees were used to define the retrognathic sample, it was of interest to know whether such a group of subjects constitutes a significant segment of the population. Therefore, all the records for children in the Growth Study between 10 years 6 months and 11 years 5 months of age were examined. Although the children in the Growth Study probably do not represent the population as a whole, there is no reason to suspect that higher socioeconomic status and greater geographic mobility influence the structures of the face in a consistent fashion.

Table I. Northwestern standards for ten cephalometric measurements and the mean values for male and female orthognathic samples used in this study

\begin{tabular}{|c|c|c|c|c|c|c|}
\hline \multirow[b]{3}{*}{ Measurement } & \multirow{2}{*}{\multicolumn{2}{|c|}{$\begin{array}{l}\text { Northwestern standards, } \\
8 \text { to } 11 \text { years }\end{array}$}} & \multicolumn{4}{|c|}{ This sample } \\
\hline & & & \multicolumn{2}{|c|}{$\begin{array}{c}\text { Males }(n=13) \\
11 \text { years }\end{array}$} & \multicolumn{2}{|c|}{$\begin{array}{c}\text { Females }(n=12), \\
11 \text { years }\end{array}$} \\
\hline & Mean & S.D. & Mean & $S . D$. & Mean & S.D. \\
\hline SNA & 80.79 & 3.85 & 79.08 & 2.61 & 80.61 & 3.36 \\
\hline SNB & 78.02 & 3.06 & 76.87 & 2.13 & 77.46 & 3.59 \\
\hline ANB & 2.77 & 2.33 & 2.21 & 1,21 & 3.15 & 1.44 \\
\hline NS-MP & 32.27 & 4.67 & 32.67 & 2.70 & 31.43 & 4.94 \\
\hline N-A-Pog. & 4.22 & 5.38 & 2.29 & 3.15 & 4.19 & 3.56 \\
\hline NS-I & 103.54 & 5.02 & 104.42 & 2.59 & 105.99 & 5.28 \\
\hline $\mathrm{I} \cdot \overline{\mathrm{I}}$ & 130.40 & 7.24 & 126.27 & 4.86 & 125.45 & 5.83 \\
\hline $\bar{M} \mathrm{P}-\overline{\mathrm{I}}$ & 93.52 & 5.78 & 97.07 & 5.26 & 96.73 & 3.74 \\
\hline OP $-\bar{I}$ & 71.79 & 5.16 & 69.32 & 4.28 & 68.67 & 4.66 \\
\hline N Pog.-I (mm.) & 6.35 & 2.67 & 7.95 & 2.26 & 7.89 & 2.19 \\
\hline
\end{tabular}


There were 12711 year records, and twenty-four of these (19 per eent) met the criteria of Class II molar relations and an ANB angle of greater than 4.5 degrees. This is about the median of the range listed by Fisk ${ }^{3}$ for twenty studies on the prevalence of malocelusion according to Angle's classification. Actually, the incidence of Class II molar relationship for 11-year-old children in the Growth Study was 38.6 per cent. However, the additional requirement of an ANB angle larger than 4.5 degrees had the effect of screening out the purely dental Class II cases from the sample.

Skeletodental retrognathism, as defined and used in this study, oceurs in approximately one fifth of a population of 11-year-old children. These children. need and frequently obtain orthodontic treatment. Indeed, they constitute a very sizable proportion of every orthodontic practice. Of the twenty-four skeletodental retrognathic children from the Growth Study, eight were already in treatment at 11 years of age, so that the molar relationship and ANB angles had to be established from earlier records. These eight were not used in the study being reported here.

METHOD

Nine vertical measurements perpendicular to the sella-nasion plane were used, as shown in Fig. 1. In addition, nine measurements along sella-nasion from sella were used to locate landmarks anteroposteriorly. These, plus the angle from sella-nasion to the mandibular plane, made a total of nineteen measurements. Uncommon cephalometric landmarks used in this study have to do with the dentition and are defined as follows:

$\mathrm{M}_{2}$ - The junction of a line tangent to the posterior surface of the maxillary first permanent molar and a curve representing the line of occlusal contact between maxillary and mandibular teeth.

$\mathrm{M}_{1}$ - The junction of a line tangent to the anterior surface of the maxillary first permanent molar and a curve representing the line of occlusal contact between the maxillary and mandibular teeth.

$\mathrm{Pm}$-The junction of a line tangent to the anterior surface of the maxillary first premolar and a curve representing the line of occlusal contact between maxillary and mandibular teeth.

Is - The tip of the crown of the most anterior maxillary central incisor.

Ii - The tip of the crown of the most anterior mandibular central incisor.

These landmarks are used to describe the position of the teeth in the face rather than the more usual occlusal plane (bisection of molar and incisor overbite), since by the age of 11 the plane of occlusion is no longer flat but curved. Also, in retrognathism the overbite is characteristically deep, so that bisection of the overbite gives a false picture of incisor position.

Since the same subject-to-film distance was used for all of the cephalograms, it was not deemed necessary to correct the measurements for enlargement. However, the enlargement factor at the midsagittal plane is 11.2 per cent.

Twenty cephalograms were retraced and measured to provide an estimate of the investigator errors. One, that for S-Ar, showed a difference at the 5 per cent 

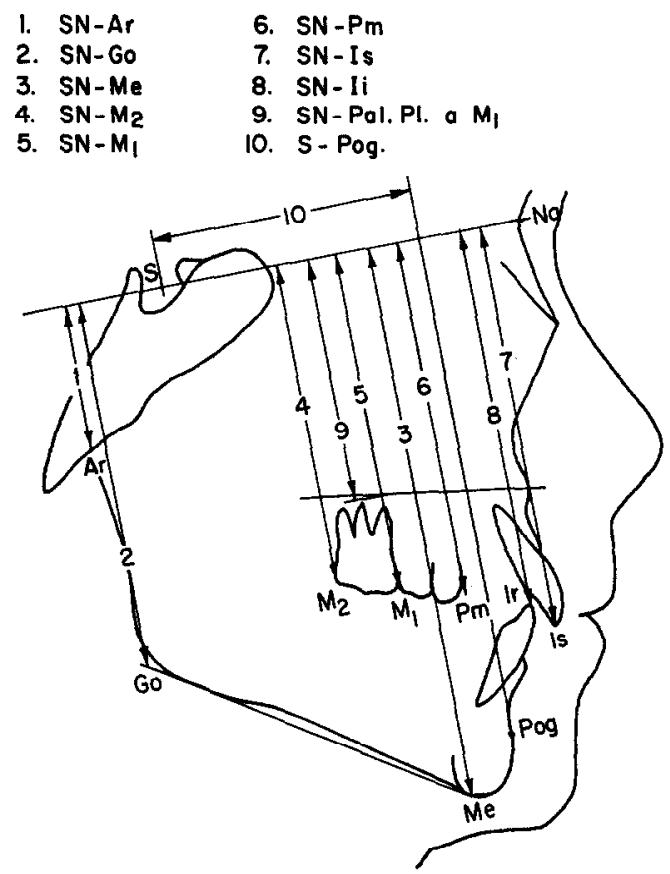

Fig. 1. The nine measurements perpendicular to $\mathrm{S}-\mathrm{Na}$ used in this study. For the sake of clarity, only one anteroposterior measurement ( $\mathrm{S}-\mathrm{P} \circ \mathrm{g}$ ) is shown. The distance from sella to each of the other eight landmarks was obtained similarly.

level of significance, apparently because of a very small variance. The average difference for all measurements was $0.24 \mathrm{~mm}$. The largest average difference of $0.58 \mathrm{~mm}$. was for S-Pm and was not statistically significant. Therefore, it is not likely that subsequent sample differences greater than $0.50 \mathrm{~mm}$. could have been created by the measurement technique except for the S-Pm measurement.

Correlations between all measurements used were also computed for the sample of fifty retrognathic subjects in order to examine certain relationships of interest.

\section{FINDINGS}

In Table II the sex differences found for the measurements used are shown for the skeletodental retrognathic sample. Each of the nine vertical measurements used shows the male subjects to be larger, on the average, than the female subjects, with five of them statistically different at the 5 per cent level of significance as shown by a Student-Fisher " $t$ " test. While only one of the anteroposterior measurements was found to be significantly different, these dimensions also tend to be larger in the male subjects. Therefore, each sex is subsequently considered separately.

Comparisons of the orthognathic sample with the retrognathic sample are listed in Table III. Of the nine vertical measurements for each sex (a total of eighteen), only two-SN-M $\mathrm{M}_{1}$ and $\mathrm{SN}-\mathrm{Is}$-were found to be significantly different 
'Table II. Sex differences betwen the sheletodental retrognathic samples

\begin{tabular}{|c|c|c|c|c|c|}
\hline \multirow[b]{2}{*}{ Measurement } & \multicolumn{2}{|c|}{$\begin{array}{c}\text { Males } \\
(n=25)\end{array}$} & \multicolumn{2}{|c|}{$\begin{array}{c}\text { Femalos } \\
(n=25)\end{array}$} & \multirow[b]{2}{*}{$" \theta "$} \\
\hline & Mean & S.D. & Mean & $S . D$. & \\
\hline \multicolumn{6}{|l|}{ Vertical } \\
\hline $\mathrm{SN}-\mathrm{Ar}$ & 29.4 & 3.1 & 27.4 & 2.5 & $2.51^{*}$ \\
\hline SN-Go & 73.4 & 4.9 & 71.7 & 4.3 & 1.31 \\
\hline $\mathrm{SN}-\mathrm{Me}$ & 114.5 & 6.4 & 110.2 & 3.6 & $2.89 \dagger$ \\
\hline $\mathrm{SN} \cdot \mathrm{M}_{2}$ & 66.5 & 3.5 & 64.7 & 2.5 & 2.03 \\
\hline $\mathrm{SN}-\mathrm{M}_{1}$ & 71.7 & 3.5 & 69.8 & 2.7 & $2.15^{*}$ \\
\hline SN-Pm & 76.5 & 4.1. & 73.9 & 3.3 & $2.43^{*}$ \\
\hline $\mathrm{SN}-\mathrm{Is}$ & 85.9 & 4.5 & 81.8 & 3.7 & 1.81 \\
\hline $\mathrm{SN}-\mathrm{Ti}$ & 78.1 & 5.3 & 74.7 & 3.4 & $2.73 \dagger$ \\
\hline SN-Pal. Pl. & 48.8 & 2.6 & 47.8 & 1.9 & 1.55 \\
\hline \multicolumn{6}{|l|}{ Anteroposterior } \\
\hline S-Ar & 20.5 & 3.1 & 20.4 & 3.3 & 0.01 \\
\hline S-Go & 18.8 & 5.6 & 17.9 & 5.6 & 0.58 \\
\hline $\mathrm{S}-\mathrm{Me}$ & 37.6 & 7.2 & 38.4 & 7.0 & -0.41 \\
\hline $\mathrm{S}-\mathrm{M}_{2}$ & 24.2 & 4.4 & 22.2 & 4.5 & 1.57 \\
\hline $\mathrm{S}-\mathrm{M}_{1}$ & 36.1 & 4.7 & 34.5 & 4.9 & 1.16 \\
\hline $\mathrm{S}-\mathrm{Pm}$ & 52.2 & $4 . \overline{5}$ & 50.6 & 4.9 & 1.24 \\
\hline S-Is & 69.3 & 6.3 & 67.5 & 6.0 & 1.02 \\
\hline S-Ii & 62.4 & 5.8 & 59.2 & 5.0 & $2.09^{*}$ \\
\hline S-Pog. & 48.1 & 6.7 & 47.7 & 6.5 & 0.20 \\
\hline
\end{tabular}

* Significant at the 5 per cent level.

tSignificant at the 1 per cent level.

at the 5 per cent level of confidence. Both are for the female sample. Therefore, the differences in vertical dimensions between skeletodental orthognathism and retrognathism in these samples are slight. However, two patterns should be noted. First, the means of the three vertical measurements which locate the mandible (SN-Ar, SN-Go, and SN-Me) are almost identical in orthognathic and retrognathic samples for both sexes. Similarly, there is no significant difference in the measurement which locates the palatal plane (SN-Pal. Pl. at $\mathbf{M}_{1}$ ). Second, the remaining five measurements, which have to do with the location of the dentition vertically, show a consistent tendency in both sexes to be greater, on the average (by about $1.0 \mathrm{~mm}$.), in the retrognathic sample. In nonc of thesc five comparisons for each sex does the reverse hold true. The differences exceed the measurement error except for SN-Ii in females. Hence, it would seem that, generally, skeletodental retrognathism of the severity studied here involves a slightly greater maxillary dentoalveolar height than does the normal. The difference does not appear to be in the upper posterior face, since the measurements from SN to palatal plane are almost identical in both groups. Furthermore, it may be seen that the differences between the normal sample and the retrognathic sample include a more curved line of occlusion in the latter, as the measurement to the mesial aspect of the first molar $\left(S N-M_{1}\right)$ has the greatest difference of 
Table III. Comparisons of the orthognathic sample with the retrognathic sample for males and for females

\begin{tabular}{|c|c|c|c|c|c|c|c|c|c|c|}
\hline \multirow{3}{*}{$\begin{array}{l}\text { Measure- } \\
\text { ment }\end{array}$} & \multicolumn{5}{|c|}{ Males } & \multicolumn{5}{|c|}{ Females } \\
\hline & \multicolumn{2}{|c|}{ Orthognathic } & \multicolumn{2}{|c|}{ Retrognathic } & \multirow[b]{2}{*}{ " $t "$} & \multicolumn{2}{|c|}{ Orthognathic } & \multicolumn{2}{|c|}{ Retrognathic } & \multirow[b]{2}{*}{ " $t "$} \\
\hline & Mean & S.D. & Mean & $S . D$. & & Mean & S.D. & Mean & S.D. & \\
\hline SN-Ar & 29.5 & 4.1 & 29.4 & 3.7 & 0.04 & 29.1 & 4.3 & 27.4 & 2.5 & 1.51 \\
\hline SN-Go & 74.9 & 4.8 & 73.4 & 4.9 & 0.88 & 72.9 & 6.7 & 71.7 & 4.3 & 0.68 \\
\hline $\mathrm{SN}-\mathrm{Me}$ & 114.0 & 5.6 & 114.5 & 6.4 & -0.24 & 109.8 & 3.9 & 110.2 & 3.6 & -0.36 \\
\hline $\mathrm{SN}-\mathrm{M}_{2}$ & 65.3 & 4.0 & 66.5 & 3.5 & -0.97 & 63.0 & 2.9 & 64.7 & 2.5 & -1.91 \\
\hline $\mathrm{SN}-\mathrm{M}_{1}$ & 69.6 & 4.2 & 71.7 & 3.5 & -1.60 & 67.4 & 2.4 & 69.8 & 2.7 & $-2.52 *$ \\
\hline $\mathrm{SN} \cdot \mathrm{Pm}$ & 75.2 & 4.2 & 76.5 & 4.1 & -0.88 & 72.7 & 2.0 & 73.9 & 3.3 & -1.21 \\
\hline SN-Is & 82.2 & 3.3 & 83.9 & 4.5 & -1.21 & 79.1 & 2.5 & 81.8 & 3.7 & $-2.27^{*}$ \\
\hline SN-Ii & 77.3 & 3.6 & 78.1 & 5.3 & -0.48 & 74.7 & 2.3 & 74.7 & 3.4 & 0.00 \\
\hline SN-Pal. Pl. & 48.2 & 2.3 & 48.8 & 2.6 & -0.68 & 47.5 & 1.6 & 47.8 & 1.9 & -0.43 \\
\hline SN-MP & 32.7 & 2.7 & 36.1 & 4.8 & $-2.31 \dagger$ & 31.4 & 4.9 & 34.3 & 4.8 & -1.70 \\
\hline $\mathrm{S}-\mathrm{Ar}$ & 18.9 & 3.4 & 20.5 & 3.1 & -1.40 & 19.4 & 2.0 & 20.4 & 3.3 & -1.02 \\
\hline S-Go & 16.7 & 3.9 & 18.8 & 5.6 & -1.23 & 16.5 & 3.9 & 17.9 & 5.6 & -0.75 \\
\hline $\mathrm{S}-\mathrm{Me}$ & 44.1 & 2.9 & 37.6 & 7.2 & $3.13 \dagger$ & 43.2 & 7.7 & 38.4 & 7.0 & 1.90 \\
\hline $\mathrm{S} \cdot \mathrm{M}_{2}$ & 24.3 & 2.4 & 24.2 & 4.4 & 0.06 & 22.9 & 3.3 & 22.2 & 4.5 & 0.49 \\
\hline$S-M_{x}$ & 36.1 & 2.6 & 36.1 & 4.7 & -0.01 & 34.7 & 4.1 & 34.5 & 4.9 & 0.07 \\
\hline $\mathrm{S}-\mathrm{Pm}$ & 52.6 & 3.3 & 52.2 & 4.5 & 0.26 & 50.5 & 4.4 & 50.6 & 4.9 & -0.04 \\
\hline S-Is & 68.2 & 2.7 & 69.3 & 6.3 & -0.56 & 66.0 & 4.9 & 67.5 & 6.0 & -0.75 \\
\hline $\mathrm{S}-\mathrm{Ii}$ & 64.5 & 3.0 & 62.4 & 5.8 & 1.22 & 62.6 & 5.0 & 59.2 & 5.0 & 1.94 \\
\hline S-Poy. & 53.9 & 2.9 & 48.1 & 6.7 & $3.00 \dagger$ & 52.9 & 6.3 & 47.7 & 6.5 & $2.31^{*}$ \\
\hline
\end{tabular}

*Significant at the 5 per cent level.

tSignificant at the 1 per cent level.

the three with respect to the posterior teeth. This, of course, is not unexpected.

Evidently, for these samples, skeletodental retrognathism does not involve a basic alteration in vertical dimensions of the face, although there is a trend toward such in the maxillary dentoalveolar portion. It is, indeed, as Fisk and colleagues, ${ }^{4}$ Harris, ${ }^{5}$ and others have reported, generally a matter of a small mandible, posteriorly positioned relative to the maxilla and cranial base. The anteroposterior figures in Table III support this. The S-Pog measurement shows significant differences between orthognathic and retrognathic samples for both boys and girls. Although not shown in this table, mandibular body length is, on the average, $3.7 \mathrm{~mm}$. shorter in the male retrognathic sample than in the male orthognathic sample and $3.8 \mathrm{~mm}$. shorter in the female retrognathic sample than in the female orthognathic sample.

Furthermore, it should be noted that the measurements of anteroposterior position of the maxillary dentition $\left(\mathrm{S}-\mathrm{M}_{2}, \mathrm{~S}-\mathrm{M}_{1}, \mathrm{~S}-\mathrm{Pm}\right.$ and $\mathrm{S}-\mathrm{Is}$ ) show virtually no difference between retrognathism and orthognathism for either males or females in these samples.

Table IV contains half of the correlation matrix of all variables used. The correlations between vertical and horizontal measurements are not shown as none exceeds 0.52 . It will be seen that vertical measurements tend to be highly 
Table IV. Correlation coefficients among all vertical measurements and among all. horizontal measurements

\begin{tabular}{|c|c|c|c|c|c|c|c|c|c|c|}
\hline \multirow{2}{*}{$\begin{array}{c}\text { Measure- } \\
\text { ment }\end{array}$} & \multicolumn{10}{|c|}{ Sella-nasion to: } \\
\hline & Ar & Go & $M e$ & $M_{2}$ & $M_{1}$ & $P m$ & Is & Ii & Pal. Pl. & l. $M P<$ \\
\hline $\mathrm{SN}-\mathrm{Ar}$ & \multicolumn{10}{|l|}{1.00} \\
\hline $\mathrm{SN} \cdot \mathrm{Go}_{\mathrm{O}}$ & 0.70 & 1.00 & & \multicolumn{7}{|c|}{ Vertical measures } \\
\hline $\mathrm{SN} \cdot \mathrm{Me}$ & 0.59 & 0.51 & 1.00 & \multirow{2}{*}{\multicolumn{2}{|c|}{1.00}} & & & & & \\
\hline $\mathrm{SN}-\mathrm{M}_{2}$ & 0.62 & 0.70 & 0.86 & & & & & & & \\
\hline $\mathrm{SN}-\mathrm{M}_{1}$ & 0.65 & 0.61 & 0.89 & 0.11 & 1.00 & & & & & \\
\hline $\mathrm{SN}-\mathrm{Pm}$ & 0.56 & 0.44 & 0.90 & -0.13 & -0.14 & 1.00 & & & & \\
\hline $\mathrm{SN}-\mathrm{Is}$ & 0.44 & 0.34 & 0.81 & -0.30 & -0.30 & -0.25 & 1.00 & & & \\
\hline SN-Ii & 0.42 & 0.39 & 0.89 & 0.75 & 0.80 & 0.88 & 0.82 & 1.00 & & \\
\hline SN-Pal. Pl. & 0.63 & 0.52 & 0.76 & 0.80 & 0.81 & 0.77 & 0.74 & 0.73 & 1.00 & \\
\hline \multirow[t]{2}{*}{$\mathrm{SN}-\mathrm{MP}<$} & -0.12 & -0.44 & 0.46 & 0.19 & 0.30 & 0.47 & 0.47 & 0.51 & 0.24 & 1.00 \\
\hline & \multicolumn{10}{|c|}{ Sella to: } \\
\hline $\begin{array}{c}\text { Measure- } \\
\text { ment }\end{array}$ & $A r$ & Go & $M e$ & $M_{2}$ & $M_{1}$ & $P m$ & $1 \mathrm{~s}$ & Ii & $\operatorname{Pog}$ & $\begin{array}{c}S N-M P \\
<\end{array}$ \\
\hline $\mathrm{S}-\mathrm{Ar}$ & 1.00 & & & & & & & & & \\
\hline S-Go & 0.68 & 1.00 & & \multicolumn{7}{|c|}{ Horizontal measures } \\
\hline $\mathrm{S}-\mathrm{Me}$ & -0.50 & -0.50 & 1.00 & & & & & & & \\
\hline $\mathrm{S}-\mathrm{M}_{2}$ & -0.49 & -0.76 & 0.84 & 1.00 & & & & & & \\
\hline$S \cdot M_{1}$ & -0.49 & -0.77 & 0.85 & 0.98 & 1.00 & & & & & \\
\hline $\mathrm{S} \cdot \mathrm{Pm}$ & -0.55 & -0.77 & 0.86 & 0.94 & 0.95 & 1.00 & & & & \\
\hline S-Is & -0.59 & -0.75 & 0.84 & 0.92 & 0.93 & 0.94 & 1.00 & & & \\
\hline $\mathrm{S}-\mathrm{Ii}$ & -0.50 & -0.68 & 0.82 & 0.87 & 0.89 & 0.93 & 0.91 & 1.00 & & \\
\hline S-Pog & -0.51 & -0.74 & 0.97 & 0.84 & 0.86 & 0.90 & 0.88 & 0.89 & 1.00 & \\
\hline $\mathrm{SN}-\mathrm{MP}<$ & -0.01 & 0.18 & -0.66 & -0.39 & -0.40 & -0.45 & -0.39 & -0.39 & -0.62 & 1.00 \\
\hline
\end{tabular}

correlated with other vertical measurements. Indeed, twenty-two of the thirtysix shown range from 0.59 to 0.90 . Similarly, horizontal measurements tend to be highly correlated with other horizontal measurements.

The angle SN-MP has been included in Table IV, and it may be seen that it does appear to be related to the anteroposterior position of the mandible at pogonion, as shown by S-Pog. Thus, the more posterior the chin (that is, the smaller the S-Pog distance), the larger is the angle SN-MP. However, a correlation of -0.62 , although statistically significant, has little practical value because of the inherently high variance involved and the very small differences dealt with. Furthmore, none of the vertical measures are correlated with the SN-MP angle to a greater degree than 0.49 . Therefore, while a steep mandibular plane angle is of considerable interest, it would appear that it occurs independently of vertical measurements in the face, at least in this sample.

\section{DISCUSSION}

In Fig. 2 a construction of the average orthognathic and retrognathic faces shows how the combination of similar vertical dimensions with a smaller, more posteriorly positioned mandible results in a steeper mandibular plane angle with 


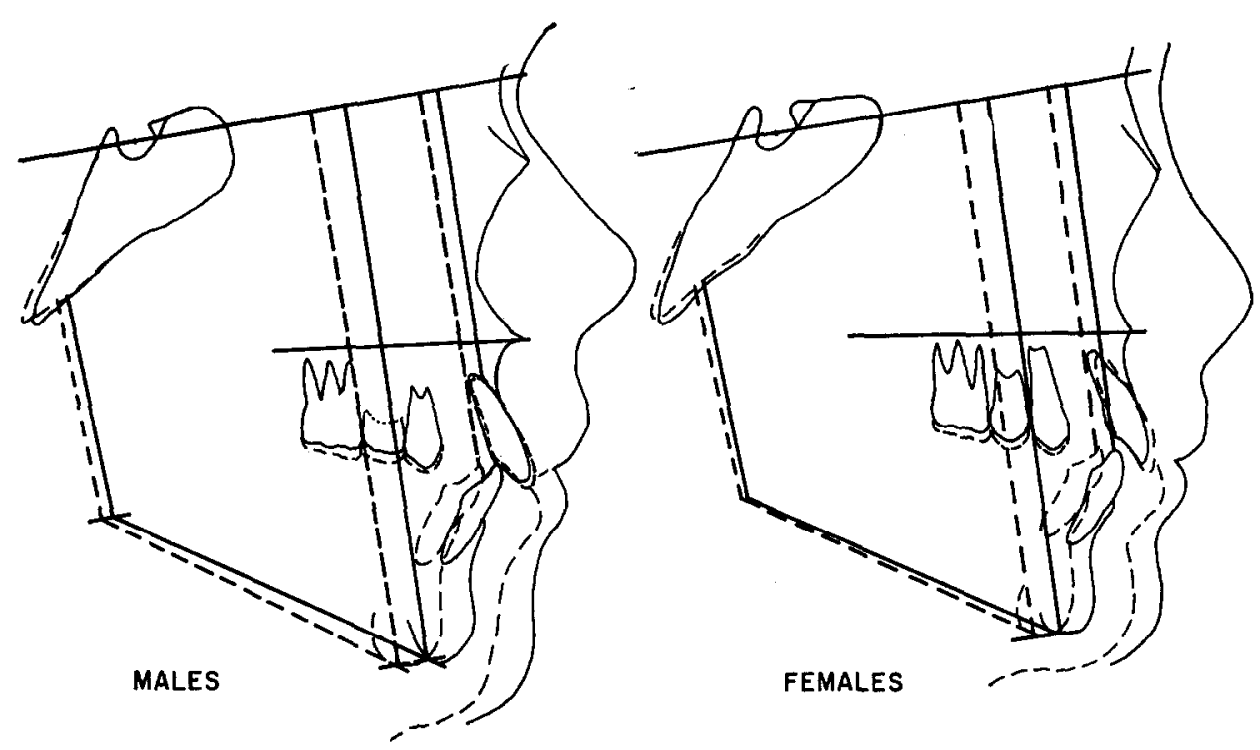

Fig. 2. Skeletodental structures constructed from average values for orthognathism and for retrognathism. Solid lines indicate average orthognathic outlines (thirteen males, twelve females). Broken lines indicate average retrognathic outlines (twenty-five males, twenty-five females).

sella-nasion in the retrognathic sample. One might wonder why the mean mandibular plane angle is not greater than was found in skeletodental retrognathism. An inspection of the standard deviations in Table III provides part of the answer. The variability of the angle SN-MP in the retrognathic samples is 4.8 degrees. Thus, while quite large angles exist in the sample, they are cancelled out in the average values by equally small angles. Of course, samples were not selected on the basis of this angle, so that large and small mandibular plane angles were included. In other words, when the criteria of severity of malocelusion are posterior position of the mandible (ANB angle greater than 4.5 degrees) and posterior position of the mandibular dentition (Class II molars), a stcep mandibular plane does not necessarily follow.

It may be seen, then, that skeletodental retrognathism of the severity studied here does not involve marked differences in vertical dimensions of the face from a normal or skeletodental orthognathic sample. A slight tendency was found for the maxillary dentoalveolar height to be greater in retrognathism than in orthognathism, which, coupled with the similarity in over-all vertical dimensions between the two groups, might suggest a compensatory mechanism for the preservation of vertical dimensions regulated by the muscular support of the mandible.

That is, given a small, posteriorly positioned mandible, supported by an unalterable length of masseter-pterygoid muscle sling, then in retrognathism the posterior position and small size of the mandible might permit an increased amount of maxillary alveolar growth. Unfortunately, for this hypothesis, there is virtually no correlation between severity as measured by S-Pog and maxillary height measurements $\left(\mathrm{M}_{2}=0.16 ; \mathrm{M}_{1}=0.05 ; \mathrm{Pm}=-0.17\right)$. It is probable that 
the mixture of subtypes in the sample has obseured any such relationship, if it exists at all.

As shown previously in a template study by Wylie and Johnson ${ }^{10}$ and in a direct study on living subjects by Pelton and Elsasser, ${ }^{7}$ male face height is greater than female face height especially after the age of 12 years. Although he did not emphasize absolute differenees, Coben ${ }^{1}$ reported more vertical growth in boys from 8 to 16 years of age than in girls and more increase in height than in depth for both sexes. In the present study it is seen that at the age of 11 , boys have larger faces than girls and the sex difference for height is greater than that for depth. Within the sexes, however, no vertical differences were found between retrognathism and orthognathism.

The possibility that the relatively highly inherited vertical dimensions of the face might be different in retrognathism and in orthognathism is not supported by the findings of this study. The significant differences between skeletodental orthognathism and retrognathism appear to lie in the anteroposterior dimensions.

\section{SUMMAKY}

This study deals with nine vertical dimensions in skeletodental retrognathism. Twenty-five boys and twenty-five girls, 11 years of age, with Class II molar relationships and $\mathrm{ANB}$ angles of 4.5 degrees or greater, were compared with twelve girls and thirteen boys, 11 years of age, with Class I molar relationships and ANB angles of less than 4.5 degrees.

The vertical dimensions used were found to be significantly larger in the boys than in the girls. The vertical position of the mandible and palatal portion of the maxilla was not found to be different in retrognathism, but there appeared to be a slight tendency for the maxillary dentoalveolar height to be greater in retrognathism than in orthognathism. On the other hand, in these samples, there was no difference between retrognathism and orthognathism in anteroposterior position of the maxillary dentition relative to sella. A significant difference was found between samples for both sexes in the mandible, which was found to be smaller and more posteriorly positioned in retrognathism than in orthognathism. It was observed that the mandibular plane angle is slightly larger in retrognathism than orthognathism. However, the size of the mandibular plane angle appears to be related only slightly to the severity of the retrognathism.

This work was supported by United States Public Health Service Grant DE 00224.10. The author is indebted to Professor Paul S. Dwyer for statistical assistance with this study.

\section{REFERENCES}

1. Coben, S. E.: The Integration of Facial Skeletal Variants: A Serial Cephalometric Roentgenographic Analysis of Craniofacial Form and Growth, AM. I. ORTHODnNTros 41: 407. $434,1955$.

2. Graber, T. M.: A Critical Review of Clinical Cephalometric Radiography, Ax. J. ORTHoDONTICS 40: 1-26, 1954.

3. Fisk, R. O.: When Maloeclusion Concerns the Public, J. Canad. D. A. 26: 397-412, 1960. 
4. Fisk, G. V., Culbert, M. R., Grainger, R. M., Hemrend, B., and Moyers R.: The Morphology and Physiology of Distoclusion, AM. J. ORThodontics 39: 3-12, 1953.

5. Harris, J. F.: Cranio-facial Growth and Malocelusion: A Multivariate Approach to the Study of the Skeletal Contribution to Class II Malocelusions, Tr. European Ortho. Soc., pp. 103-119, 1965.

6. Hunter, W. S.: A Study of the Inheritance of Craniofacial Characteristies as Seen in Lateral Cephalograms of 72 Like-Sexed Twins, Tr. European Ortho. Soc., pp. 59-70, 1965.

7. Pelton, W. J., and Elsasser, W. A.: Studies of Dento-facial Morphology. IV. Profile Changes Among 6,829 White Individuals According to Age and Sex, Angle Orthodontist 25: 199-227, 1965.

8. Sassouni, V., and Nanda, S.: Analysis of Dento-facial Vertical Proportions, AM. J. ORTHODONTICS 50: 801-823, 1964.

9. Schudy, F. F.: Vertical Growth Versus Anteroposterior Growth as Related to Function and Treatment, Angle Orthodontist 34: 75-93, 1964.

10. Weinberg, H., and Kronman, J. H.: Orthodontic Influence Upon Anterior Face Height, Angle Orthodontist 36: 80-88, 1966.

11. Wylie, W. L., and Johnson, E. L.: Rapid Evaluation of Facial Dysplasia in the Vertical Plane, Angle Orthodontist 22: 165-182, 1952. 